\title{
Gradations of interpretability in spoken complex word recognition
}

Swetlana Schuster

University of Oxford, UK

Aditi Lahiri

University of Oxford, $U K$

Corresponding author: Swetlana Schuster

Authors' institution and e-mail addresses:

Faculty of Linguistics, Philology and Phonetics

Clarendon Institute

Oxford OX1 2HG

University of Oxford, U.K.

E-mail: swetlana.schuster@ling-phil.ox.ac.uk

E-mail: aditi.lahiri@ling-phil.ox.ac.uk 


\title{
Gradations of interpretability in spoken complex pseudowords
}

\begin{abstract}
In an ERP experiment with cross-modal priming, we found evidence for graded interpretability of complex pseudowords, expressed as differences in the degree of priming between a complex pseudoword and its embedded base word. Only pseudowords that were constructed according to the morphological constraints of the language (for instance that nouns suffixed in $\{-u n g\}$ in German must be derived from a verbal base) led to significant attenuation of the N400 component relative to an unrelated control. Novel formations that consisted of the concatenation of a stem and affix regardless of their combinability (e.g. wirr (A., 'confused') and \{-lein\} suffix in German) did not modulate the N400 component. Moreover, gradations in degree of priming were observed with novel pseudowords that were the result of several morphological operations as a function of the composition of the full sequence of morphological operations. Any positions within the sequence that were filled by possible, but non-existing formations (thus compare hübsch (A., 'pretty') > *hübschen (V., 'beautify') > *Hübschung (N., 'beautification') versus spitz (A., 'sharp') > spitzen (V., 'sharpen') > *Spitzung (N., 'sharpening'), whereby in the former the intermediate position is expressed through a possible, but non-existing verb form) led to reduced activation of the base word. These findings corroborate previous behavioural and neuroimaging results in visual word recognition that found support for step-wise morphological decomposition in multi-affixed pseudowords and reveal that the composition of the derivational path can lead to gradations of interpretability in the recognition of spoken complex pseudowords.
\end{abstract}




\section{Keywords:}

morphological decomposition; N400; cross-modal priming; lexical decision task;

pseudowords; morphological rules 


\section{Introduction}

Variation in the speech signal is ubiquitous. It is, for instance, uncontroversial that no word may ever be pronounced in exactly the same way, even by the same speaker (Lahiri, 2012). For morphologically simple words, on the speech sound processing level, it is thus assumed that a system must be in place that is able to map a variety of possible surface realisations of a particular speech sound onto a stored representation, although the precise implementation of the system is subject to debate (Lahiri \& Reetz, 2002 for an abstractionist approach; Bybee, 2001 for a full-specification model; Pierrehumbert, 2016 for a hybrid model of speech recognition). Evidence from experiments as early as two decades ago (e.g. by Connine, Blasko \& Titone (1993)) suggests that our speech recognition system demonstrates not only flexibility in the recognition of subtle differences of a sound, but can also accommodate deviations from an expected input. Thus, non-existing forms that are constructed on the basis of an existing word and that only differ from the intended word in one or two phonological features $\left({ }^{*}\right.$ GORONET from the real word CORONET) still activate the originally intended word. As soon as the realisations deviate from the intended form in a greater number of phonological features (*HORONET from CORONET), the activation of the intended real word becomes less reliable, thereby revealing gradations in interpretability of non-existing forms depending on their phonological distance from the original word.

Our research focuses on complex words such as happiness made up from happy and ness. Earlier results raise the question to what extent gradations in interpretability are observed beyond the phonological level, allowing structural (and not just sound-related) violations to be more permissible than others. The intuition that gradations in interpretability could be possible is based on the breadth of different constraints that underlie the construction of morphologically complex words. Firstly, there are phonological constraints on word formation as in the formation of the comparative in English, whereby the comparative suffix $\{-e r\}$ can only attach 
to mono- and disyllabic bases (e.g. big > bigger or lucky > luckier). Bases consisting of more than two syllables do not form the comparative in $\{-e r\}$ (e.g. *beautiful-er or *magnificent-er). Secondly, affixes may exhibit restrictions on the word category of the base to which they attach. For example, the suffix $\{-l y\}$ can attach to adjectives, but not verbs, to form adverbs (e.g. slowly, rapidly, but *walk-ly or *help-ly) or to nouns to form adjectives (e.g. manly, scholarly; see Isitt, 1983 or Marchand, 1969). In linguistic theory, the two suffixation processes (the derivation of adverbs in $\{-1 y\}$ from adjectives and the derivation of adjectives from nouns) have been considered distinct with a homophonous suffix $\{-1 y\}$ (cf. Aronoff, 1976), but psycholinguistic or neurolinguistic investigations of this question remain to be carried out. Thirdly, there can be constraints not only on the word class of the base, but also on its provenance such that the suffix $\{-i t y\}$ will select bases of Latinate origin as in intensity, absurdity, chastity, dexterity while *happ-ity, although also formed on the basis of an adjectival base happy, would be considered deviant due to the non-Latinate origin of the base word happy. Given the range of structural constraints that are operative in the formation of morphological complexity, it is possible that some violations lead to greater interpretability than others.

Constraints on word formation provide important generalizations regarding structural violations in a given language, but they do not signal when a word form is possible, but nonexisting. For example, in suffixation with $\{-n e s s\}$, although nominalizations in $\{-n e s s\}$ from adjectives are frequent, lexical gaps can occur such that *summeriness, while structurally wellformed, is not commonly attested. This is not to say that such lexical gaps are not occasionally encountered in reference works such as Merriam-Webster. Native speakers may nonetheless hesitate in making strong claims about the existence of such words in their language. These words are possibly used by language learners or when temporary recall fails since they do not violate constraints. Lexical gaps are forms, which do not occur, but which are not impossible and which could become words at some point. Our paper focuses on these issues. 
To contextualise our study, however, we first examine the literature on structural violations so that we can justify our technique. As a technique that offers a high temporal resolution in the processing of complex cognitive processes, electrophysiology has been used extensively in the detection of structural violations in morphological processing (Leinonen, Brattico, Järvenpää \& Krause, 2008; Linares, Rodriguez-Fornells \& Clahsen, 2006; Lück, Hahne \& Clahsen, 2006; Morris \& Holcomb, 2005; Penke, Weyerts, Gross, Zander, Münte \& Clahsen, 1997). The majority of these violation studies have focused on inflectional patterns, largely verbs (e.g. comparing *bringed instead of brought). More recently, the focus has shifted towards violations of structural constraints in word formation. Bölte, Jansma, Zilverstand and Zwitserlood (2009), for instance, investigated the processing of different types of violations in the derivation of complex adjectives in German. Participants were presented with sets of sentences containing existing derived adjectives such as freundlich (A., 'friendly'), nearsynonymous derived pseudowords such as *freundhaft for which the combination of base and suffix is licensed by the morphological rules of the language, as well as a pseudoword condition in which the combination of base and suffix represents a structural violation (e.g. *freundbar in which the suffix $\{-b a r\}$ requires a verbal, rather than a nominal base). A similar constellation of English forms would be *sincereness (morphologically licensed) or *sinceric (structural violation) instead of sincerity. Significant differences between the existing condition and the two pseudoword conditions were found in a time window of $450-500 \mathrm{msec}$ after stimulus onset, consisting of a left-lateralised frontal negativity that was interpreted as a LAN effect. The absence of a significant difference between the two pseudoword conditions was traced back to the impossibility of finding a 'structural match' for the combination of the base and suffix that is common to both conditions. Previous research had shown LAN effects to occur in a number of violations of morphosyntactic constraints for inflected forms. Inflected forms in morphology refer to particular realisations of a given lexeme depending on the intended morpho-syntactic 
category. Thus, the gerund of the English verb walk is walking and therefore different from the corresponding past tense form walked, where the morphosyntactic category is realised as the regular past tense $\{-e d\}$ suffix. Examples of inflectional phenomena investigated in the literature include misapplications of regularisation processes to irregular forms (e.g. Penke et al., 1997 for German *geladet instead of geladen (past participle for V., 'load'; English comparison *singed instead of sung) where the regular form of the participle is not expected for the strong verb laden (V., 'load')) and in the selection of the default theme vowel when particular roots require a lexically specified theme vowel (Rodriguez-Fornells, Clahsen, Lleó, Zaake \& Münte, 2001). Some effects that have been associated with a LAN component may, however, also be taskrelated. In the present study, we are interested in derivational morphology, which, unlike inflectional morphology, is concerned with the formation of new lexemes based on a morphologically related word, often via the addition of affixes (cf. writ-er from write through the addition of the suffix $\{-e r\})$. In the context of derivational morphological processing, Bölte, Schulz and Dobel (2010) found the same three sets of German existing and non-existing adjectives as in the Bölte et al. (2009) study to elicit an N400m when embedded in an MEG experiment that required participants to attend to the word class of the experimental stimuli more carefully. In this later study, there was a graded effect in the N400 response with anomalous non-existing items (e.g. *freundbar) yielding a stronger N400 effect than semantically interpretable non-existing derived adjectives such as *freundhaft. Existing German derived adjectives showed the lowest N400 response, suggesting that the integration of these items was more straightforward than for the two sets of non-existing items.

A second technique that has been employed to examine the effect of structural violations on processing is the mismatch negativity technique (or 'MMN'). The mismatch negativity technique is sensitive to perceptual change in the processing of a deviant (rare) stimulus within the context of a frequently occurring standard stimulus. Two different types 
of MMN have been reported in response to spoken words that display particular types of violations. A 'lexical MMN' has been found in $\mathrm{MMN}$ experiments that contrast the processing of existing words with matched pseudowords (Shtyrov \& Pülvermüller, 2002; Pülvermüller et al., 2001). In this case, the passive oddball paradigm revealed a higher MMN for existing words than for pseudowords when the former were presented as deviants. In a different set of experiments, it has been found that ungrammatical combinations of words and morphemes give rise to stronger MMNs than licit combinations of morphemes (see Pulvermüller, Shtyrov, Hasting \& Carlyon, 2008). This type of MMN has been termed 'syntactic MMN' and has been interpreted as an index of automatic recognition of ungrammatical structure. Bakker, MacGregor, Pulvermüller and Shtyrov (2013) showed that over-regularised new forms such as *flied as deviants when the infinitival form fly is the standard elicited syntactic MMNs, suggesting that the incorrect formation of the past tense for $f l y$ was not processed like a pseudoword, but as the result of a misapplication of a combinatorial rule. The possibility of dissociating whole-word retrieval ('lexical MMN') from combinatorial violations ('syntactic MMN') also opened up the possibility of studying derivational processing using mismatch negativity.

Turning to violations which had both a structural as well as a prosodic dimension, Hanna and Pulvermüller (2014) examined the processing of derived pseudowords in German such as *Sauberheit and *Sicherkeit. For both non-existing items, it is the other nominalisation suffix that yields an existing word of the language. Thus, Sauberkeit (N., 'cleanliness') and Sicherheit (N., 'safety') are existing German words. In an MMN design, the stem forms sicher (A., 'safe') and sauber (A., 'clean') served as the standard stimulus, which was either followed by the correctly derived complex word (Sicherheit or Sauberkeit) or by a formation in which the respective suffix was not selected appropriately ( $*$ Sicherkeit and *Sauberheit). It was found that the existing complex words Sicherheit and Sauberkeit 
gave rise to a stronger MMN effect than the illicit formations *Sicherkeit and *Sauberheit, suggesting a lexical rather than a syntactic MMN in this case and therefore whole word storage, rather than combinatorial composition of derived words.

Hanna and Pulvermüller (2014) refer to the distribution of the two variants $\{-k e i t\}$ and $\{-h e i t\}$ as arbitrary and therefore not subject to structural constraints. However, Janssen, Wiese and Schlesewsky (2006) treat these violations as a mixture of prosodic versus morphosyntactic violations. For the morphosyntactic violation, the property of $\{-u n g\}$ derivations requiring a verbal, and not an adjectival base, was used to investigate the processing of formations such as *Vollung (N., 'act of making full') that were based on the adjectival stem voll (A., 'full'). Prosodic violations were studied on the basis of formations that parallel the set of stimuli used in Hanna and Pulvermüller (2014). Unlike Hanna and Pulvermüller, Janssen et al. (2006), however, refer to the two suffixes $\{$-heit $\}$ and $\{-k e i t\}$ as occurring in complementary distribution (Fleischer, Barz \& Schröder, 1995). It is argued that the suffix $\{-k e i t\}$ is selected over $\{-h e i t\}$ when the preceding syllable is unstressed, whereas monosyllabic bases and preceding syllables that are stressed require the suffix $\{-h e i t\}$. N400like rather than LAN effects were found for the prosodic violations in *Korrektkeit and *Einsamheit, suggesting that these formations were processed like viable pseudowords given the absence of a morphosyntactic violation for these items.

The authors were, however, also surprised to find an N400, rather than a LAN effect for the morphosyntactic violations (e.g. *Vollung), with an even stronger negativity for these formations. This raises the question we ask in this paper: to what extent can constructions such as *Vollung only be interpreted to be combinations of a base adjective and the suffix $\{-$ ung\}? Verbs can be productively derived from adjectives in German without the addition of an overt derivational marker (thus, voll (A., 'full') $>$ voll-en (V., 'to fill') where the suffix $\{-$ $e n\}$ is not a derivational, but an inflectional marker to denote the citation form. As illustrated 
in Figure 1, there are thus two ways in which nouns ending in $\{-u n g\}$ can be derived in German. Nouns formations in $\{-u n g\}$ can either be directly based on a verb (e.g. ahnen (V., 'to suspect', 'to guess') > Ahnung (N., 'inkling', 'hunch')) as shown in (A) or the verb can serve as an intermediate step in a two-step derivation from a basic adjective as in (B) (e.g. heil (A., 'whole, intact') > heilen (V., 'to heal') > Heilung (N., 'healing')). While there is no direct path to connect an adjective to a noun-formation in $\{-u n g\}$, adjectives can thus still participate in the derivation of a noun in $\{-u n g\}$ via an intermediate structural level represented by a verb.

A

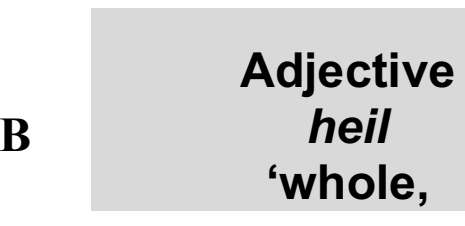

Verb
ahnen
to guess' $\quad \begin{gathered}\text { Noun } \\ \text { Ahnung } \\ \text { 'inkling' }\end{gathered}$

\section{Noun} Heilung 'healing'

Figure 1 Derivational paths available for nominalisations in $\{-$ ung\}

Note, however, that the structure in (B) is not considered by Janssen et al. (2006). This could be due to the fact that the literature considers forms with a single overt suffix to be always the result of a single morphological operation; e.g. voll + ung. However, as we noted above, $\{-$ ung \} can only be added to verbs; thus the adjective voll must be converted to a verb and then the suffix $\{-u n g\}$ can be added. This is similar to the suffix $\{-i n g\}$ in English which cannot be added to nouns (cf. *door-ing) and thus the form eyeing has to come from (an) eye $(N)>($ to $)$ eye $(V)>$ eyeing. Hence, if there is an increase in morphological complexity, the importance of morphological constraints becomes even more pertinent as there is a possibility for the effect of morphological constraints on processing to be additive which the results in Jansen et al. (2006) seem to hint at. 
Intermediate levels of structural complexity have indeed only recently been considered in a number of behavioural and neuroimaging studies (e.g. Meinzer, Lahiri, Flaisch, Hannemann \& Eulitz, 2009; Pliatsikas, Wheeldon, Lahiri \& Hansen, 2014; Schuster \& Lahiri, 2018; Schuster, Scharinger, Brooks, Lahiri \& Hartwigsen, 2018; Wheeldon, Schuster, Pliatsikas, Malpass \& Lahiri, 2018). In two of these studies (Schuster \& Lahiri, 2018; Schuster et al., 2018), distinct processing signatures were identified for different sets of pseudowords, depending on factors relating to the internal composition of their morphological structure. The focus of these studies, however, has always been on the visual recognition of morphologically complex forms using either a lexical decision task with visual delayed and/or masked priming (e.g. Schuster \& Lahiri, 2018; Wheeldon et al., 2018) or a simple lexical decision task in the fMRI studies (e.g. Meinzer et al., 2009; Pliatsikas et al., 2014; Schuster et al., 2018), thereby failing to address how auditorily presented multisuffixed complex words and pseudowords are processed and to what extent these can activate the meaning of the base word.

Thus, in the present study, we propose to focus on the processing of three different types of non-existing spoken forms using electrophysiology in a cross-modal design. While cross-modal priming studies with morphologically related words have been extensively used in the field since Marslen-Wilson et al. (1994), the majority of these studies have been run using behavioural, rather than electrophysiological measures. Nonetheless, the results of these studies (e.g. Marslen-Wilson et al., 1994; Meunier \& Longtin, 2007) provide an insight into the cognitive mechanisms at work during cross-modal priming. Unlike masked priming, which has been argued to be prelexical and morpho-orthographically driven (cf. Rastle et al., 2004; Longtin \& Meunier, 2005; Grainger \& Beyersmann, 2017), cross-modal priming taps into central, modality-independent presentations (Marslen-Wilson et al., 1994). This contrast between masked and cross-modal priming, especially with regard to nonword processing, 
becomes evident in the results obtained for Longtin and Meunier (2005) versus Meunier and Longtin (2007) using the same set of novel forms in French. In the masked priming study (i.e. Longtin \& Meunier, 2005), any novel form in French that could be morpho-orthographically segmented into a stem and a suffix (e.g. sport + ation or rapide + ifier) led to decomposition, while the cross-modal design (i.e. Meunier \& Longtin, 2007) only led to priming effects in forms that were morphologically viable and therefore semantically interpretable. Thus, in the latter study, *rapidifier (V., 'quickify') primed rapide (A., 'quick'), but *sportation (N., 'act of sporting') did not prime sport (N., 'sport'). Differences between masked and overt priming have also been shown using electrophysiological measures. Thus, while Morris et al. (2011) found equivalent priming effects for existing derived words in English (e.g. flexible), nonwords composed of illegal combinations of stems and affixes (e.g. *flexify) and nonwords that were not composed of any identifiable morphological constituents (e.g. *flexint) in masked priming, Smolka, Gondan and Rösler (2015) demonstrated a modulation of the reduction of the N400 component in (visual) overt priming. This modulation depended on the morphological relationship between verbs and their prefixed versions in German. Given the earlier behavioural evidence with cross-modal priming in nonword processing (cf. Meunier \& Longtin, 2007), we believe that the method lends itself to an investigation of central, modality-independent representations using electrophysiological measures.

The novelty of our study consists in the reliance on forms that are multi-suffixed through the existence of different derivational chains; that is the pseudowords have different properties. Our prediction is that any non-existing items that are interpreted to be possible pseudowords should activate the base from which they are derived; this should not occur with forms which do not conform to the rules of the language. We expect this activation to be driven by the availability of a morphologically viable derivational path as depicted in Figure 
1. Conversely, this means that any non-existing item that is not the result of a viable derivational path should not activate an embedded adjective.

Moreover, we also expect that speakers will not only be sensitive to the distinction between morphological viability and impossibility based on morphological constraints, but also to degrees of viability based on the composition of the derivational path. Recall that lexical gaps were defined as structurally well-formed compositions, which are (not yet) existing words in the language. As soon as we are dealing with complex forms that could be the result of multiple derivations, lexical gaps can occur at different points within the derivational path. Our expectation is that the more lexical gaps occur within a derivational path, the less straightforward the integration of the non-existing form should be as the distance to an existing lexical representation increases. For the derivational path ADJECTIVE $>$ VERB $>$ NOUN in $\{-u n g\}$ given in Figure 2, a non-existing form such as *Spitzung for which only the final noun constitutes a lexical gap, should enable the recognition of the base adjective spitz more than a matched non-existing item such as *Hübschung for which both the final noun form and the intermediate verb are lexical gaps.

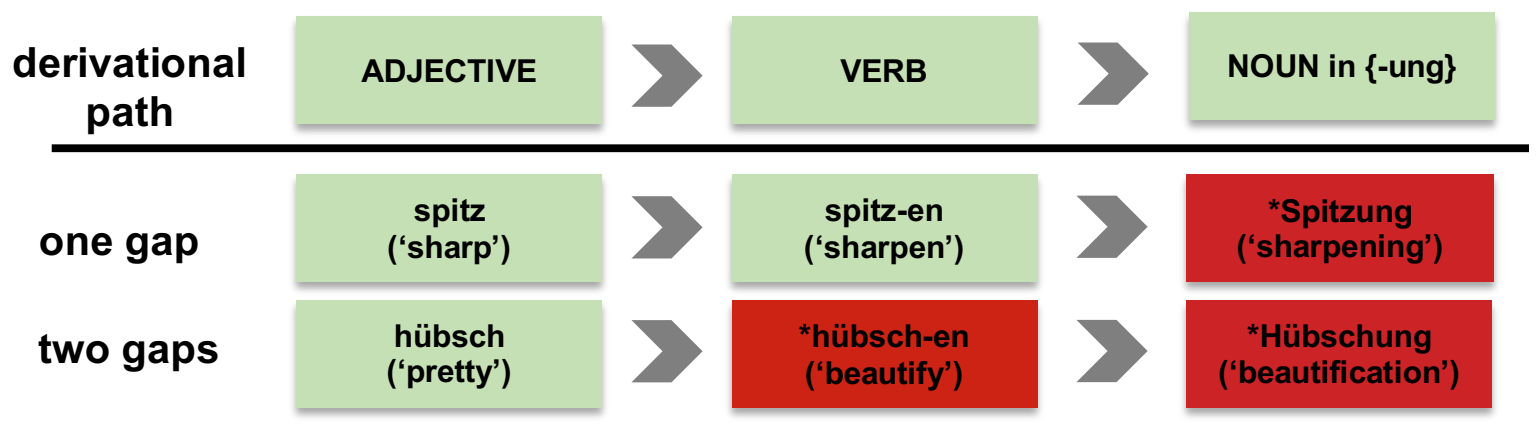

Figure 2 Novel forms built on the basis of an existing derivational path. Lexical gaps are shaded in red. Existing lexical representations are shaded in green.

In the present experiment, we included both sets of pseudoword conditions (e.g. *Spitzung and *Hübschung) as well as impossible formations such as *Wirrlein that cannot be the result of a derivational path with the objective of assessing the extent to which an embedded adjective would be activated. Although the evidence for the processing of existing words 
such as Heilung (through heil (A., 'whole', 'intact') > heilen (V., 'to heal') > Heilung (N., 'healing') was somewhat more difficult to interpret in our pre-studies (Schuster \& Lahiri, 2018; Schuster et al., 2018), we also included this condition in the present design to have a baseline comparison of priming. In a cross-modal priming experiment (prime presented auditorily and target visually), we only expect to see a reduction in the N400 response to base words that follow morphologically viable formations (cf. Meunier \& Longtin, 2007 for the corresponding behavioural evidence). Thus, impossible formations such as *Wirrlein should not activate the embedded existing adjective wirr (A., 'confusing') since the suffix $\{$-lein $\}$ requires a nominal, rather than an adjectival base. Moreover, we expect that the lexical gap in intermediate positions for items such as *Hübschung would result in these items being felt to be less interpretable than pseudowords for which the intermediate position exists (e.g. *Spitzung). Given that cross-modal priming is sensitive to a semantic relationship between prime and target, we expect to find a greater reduction in N400 amplitude for the *Spitzung than for the *Hübschung set.

\section{Methods}

\subsection{Participants}

Twenty-one native speakers of German aged 20 to 31 (mean age $=24.6, \mathrm{SD}=2.95$ ) participated in the EEG experiment. All participants were right-handed as assessed through the Edinburgh Handedness Inventory (Oldfield, 1971) and had normal or corrected-to-normal vision and no hearing impairments. Participants reported no history of psychological or neurological disorders and no hearing or reading impairments. All participants gave their informed consent for participation and were reimbursed appropriately for their time. The conduct of the study was approved by the local ethics committee (CUREC-University of Oxford). 


\subsection{Stimuli}

\subsubsection{Stimulus selection}

The experiment consisted of four experimental conditions containing 40 prime-target pairs per condition. In order to counterbalance for the number of words and nonwords in prime and target positions across the experiment, corresponding filler items were included in order to obscure the purpose of the manipulations across the experimental conditions.

Each target word was associated with two types of primes - a related complex prime containing the target item and an unrelated control baseline item. The construction of the related prime was dependent on the characteristics of the relevant experimental condition. In Condition 'Extant', an existing morphologically complex word (e.g. Heilung) was paired with the corresponding stem heil. Conditions 'NonEx1' and 'NonEx2' consisted of pairings between morphologically complex primes and their stems; condition 'Control NonEx' was constructed as a control condition in which the prime item contained the target word, but was followed by a morphologically impossible suffix or suffix combination. Table 1 gives an overview of the stimuli characteristics selected in all conditions.

Table 1. Summary of characteristics of experimental conditions

\begin{tabular}{|c|c|c|c|}
\hline CONDITION & DERIVATIONAL PATH & PRIME-TARGET & DEGREE OF N400 \\
\hline & & PAIRING & ATTENUATION \\
\hline
\end{tabular}

\begin{tabular}{l|lll}
\hline EXTANT & heil $>$ heilen $>$ Heilung & Heilung - heil & ++ \\
NONEX1 & spitz $>$ spitzen $>$ *Spitzung & *Spitzung - spitz & ++ \\
NONEX2 & hübsch $>$ *hübschen & *Hübschung - hübsch & + \\
CÖ̈bschung & No derivational path & $*$ Wirrlein - wirr & - \\
NONEX & &
\end{tabular}


All prime words were complex formations in German that were either formed following viable constraints on German word formation (conditions 'Ex', 'NonEx1' and 'NonEx2') or consisted of non-existing items for which there is no existing derivational path (condition 'Control NonEx'). The corresponding targets were all existing German adjectives or verbs. These can serve as bases for deriving the nouns in conditions 'Ex', 'NonEx1' and 'NonEx2' through the two morphological rules given in a). and b).

\section{a.) adjective $>$ zero-derived verb $>$ noun in $\{$-ung $\}$}

b.) verb $>$ adjective in $\{$-bar $\}>$ noun in $\{-$ keit $\}$

Unrelated controls in each condition were matched in lexical status, length, syllable structure and stress with their corresponding related controls, but were not semantically, morphologically or phonologically related to their target words. Targets across all four experimental conditions were matched in length $(p>.64)$, lemma and word frequency $(p>$ $.99)$ and morphological family size $(p>.12)$. As in our previous two studies (i.e. Schuster \& Lahiri, 2018; Schuster et al., 2018), the 'non-existence' of the prime words in conditions 'NonEx1', 'NonEx2' and 'Control NonEx' was validated through the CELEX (Baayen, Piepenbrock, \& Gulikers, 1995) and DWDS (Klein \& Geyken, 2010) databases and confirmed through offline rating tasks.

\subsubsection{Stimulus recording}

All experimental and filler prime words were recorded by a female native speaker of German. Recordings (sampling rate of $44.1 \mathrm{kHz}$ ) took place in a sound-attenuated booth using a Roland NT-USB microphone connected to a MacAir laptop running Audacity software (version 2.0.6). The volume of all recordings was subsequently equalized in Audacity software, but no other acoustic manipulations were performed on the naturally spoken stimuli. 


\subsection{Procedure}

Participants were seated in a sound-attenuated booth approximately $1 \mathrm{~m}$ away from a 20 -inch screen on which the visual target stimuli were displayed. Participants were first presented with the auditory stimuli via headphones. These were followed by visually presented target words (ISI $=350 \mathrm{~ms}$ ) with a display time of $750 \mathrm{~ms}$. Participants were asked to decide as quickly and as accurately as possible whether or not the item on the screen was an existing word in the German language and to press the button on the response box to nonword targets only. As only existing words were submitted to subsequent EEG data analysis, this allows the analysis of electrophysiological data for the target words (which were all existing words), independently from possible artefacts induced by the button press. Each experimental session was preceded by a practice session consisting of 10 prime-target pairs to familiarize participants with the experimental set-up. The actual experiment consisted of four experimental blocks that were separated by short breaks to minimize the effects of fatigue.

\subsection{EEG data acquisition}

Electrophysiological data were recording using a BioSemi Active Two amplifier from 64 sintered $\mathrm{Ag} / \mathrm{AgCl}$ pin electrodes. Online referencing was performed to both mastoids and eye moments were recorded using four facial electrodes (IO1, IO2, LO1, LO2), which were placed under and next to the participant's eyes. All participants took part in a short eyemovement task prior to the experiment to enable identification of eye movement artefacts by subsequently applying an EOG correction algorithm (Ille, Berg \& Scherg, 2002) to the experimental data. Electrode impedances did not exceed $20 \mathrm{mV}$. Digitisation of the signal was performed at $2048 \mathrm{~Hz}$. 


\subsection{Data analysis}

\subsubsection{Behavioural data}

Error rate data were collected to ascertain task compliance only. Overall, all participants were attentive to the task as evidenced by high accuracy scores in the nonword identification task $($ mean $=97.2 \%, \mathrm{SD}=0.83 \%)$.

\subsubsection{ERP analysis}

A $0.01 \mathrm{~Hz}$ High-Pass and a $30 \mathrm{~Hz}$ Low-Pass filter were applied to the acquired EEG data. Eye movement artefacts were identified using an EOG correction algorithm based on scalp topographies of the respective eye movement artefacts. Visual inspection of the EEG data was performed by an experienced EEG researcher. This was followed by an automatic rejection procedure for trials with an amplitude of over $90 \mu \mathrm{V}$ or a gradient exceeding $75 \mu \mathrm{V}$, using BESA analysis software (version 6.0). Noisy electrode channels were interpolated, avoiding the interpolation of more than three channels within a ROI and more than two adjacent channels within or across ROIs. Only participants for whom at least $75 \%$ of trials per condition were accepted, were included in the subsequent analysis, resulting in the exclusion of data for two participants.

A pre-stimulus-onset baseline of $200 \mathrm{~ms}$ was selected for all targets. The averaging epoch was set to $-200 \mathrm{~ms}$ to $1000 \mathrm{~ms}$ in relation to target onset. The amplitude of the N400 response to targets was calculated within the time window of $350 \mathrm{~ms}$ to $550 \mathrm{~ms}$ following target onset. Only correctly classified targets were included in the analysis. Regions of interest were computed based on previous research focusing on the N400 component by Roberts, Kotzor, Wetterlin and Lahiri (2014) using a 3x3 grid and thus the following electrode distribution: anterior-left (AF7, F3, F5 and F7), anterior-middle (Fp1, Fpz, Fp2, AF3, AFz, AF4, F1, Fz and F2), anterior-right (AF8, F4, F6 and F8), centre-left (FT7, FC5, 
FC3, T7, C5, C3, TP7, CP5 and CP3), centre-middle (FC1, FCz, FC2, C1, Cz, C2, CP1, CPz

and CP2), centre-right (FC4, FC6, FT8, C4, C6, T8, CP4, CP6 and TP8), posterior-left (P3, P5, P7, P9 and PO7), posterior-centre (P1, Pz, P2, PO3, POz, PO4, O1, Oz and O2), and posterior-right (P4, P6, P8, PO6, PO8).

\section{Results}

Two participants were excluded due to the rejection of more than $30 \%$ of trials in at least one experimental condition. All participants were very accurate in the nonword target classification task with a mean accuracy of $97.2 \%(\mathrm{SD}=0.83 \%)$, demonstrating task compliance for all participants included in the analysis of the ERP data. The visual inspection of the N400 effect revealed an attenuation of the N400 response to related words relative to their respective unrelated control stimuli in all morphologically possible conditions ('Extant', 'NonEx1', 'NonEx2'), but not in the control condition ('Control NonEx'). Difference waveforms were calculated subtracting the related from the unrelated response for each participant in the experimental conditions. In a linear mixed model with the fixed factors ROI, Prime-Type (Related vs. Unrelated) and Base and the random effects Subject and Electrode (nested under $R O I$ ), the following effects reached significance: the main effect of ROI F $(8,54)=4.52, \mathrm{p}<.001 ;$ the main effect of Prime-Type $\mathrm{F}(1,9432)=135.98, \mathrm{p}<.0001$ and the main effect of Base $\mathrm{F}(3,9432)=123.09, \mathrm{p}<.0001 .^{1}$ The interaction between PrimeType and Base was also significant at $\mathrm{F}(3,9432)=28.75, \mathrm{p}<.0001$ and was followed up by planned comparisons for the unrelated - related N400 responses for each Base condition. An overview of the LMM model and the results of the planned comparisons are given in Table 2.

\footnotetext{
${ }^{1}$ Note that since $J M P$ only allows the specification of random intercepts, rather than both random intercepts and slopes, we decided to run a complementary analysis in $R$ to establish the reliability of our results. Through model comparison, we found that a model with random intercepts and slopes for Relatedness within Subjects and Electrodes (nested under ROI) was the most complex model to converge and showed the best model fit. Again, the interaction between Relatedness and Base reached significance in a model comparison with and without the relevant interaction at $\mathrm{p}<.0001$. Pairwise follow-up comparisons showed no priming in 'Control NonEx' ( $\mathrm{t}=-0.63)$, and significant priming in 'Extant' $(\mathrm{t}=2.9)$, 'NonEx1' $(\mathrm{t}=4.2)$ and 'NonEx2' $(\mathrm{t}=2.5)$. The overall patterns thus remain unchanged regardless of the random effect structure.
} 
Table 2. Overview of LMM effects

\begin{tabular}{|c|c|c|c|c|}
\hline \multicolumn{5}{|c|}{ Overview of LMM effects } \\
\hline Effect & DF & DFDen & F Ratio & Prob $>$ F \\
\hline ROI & 8 & 54 & 4.52 & $<.001^{*}$ \\
\hline Prime-Type & 1 & 9432 & 135.98 & $<.0001 *$ \\
\hline ROI*Prime-Type & 8 & 9432 & 8.14 & $<.0001 *$ \\
\hline Base & 3 & 9432 & 123.09 & $<.0001^{*}$ \\
\hline ROI*Base & 24 & 9432 & 1.34 & 0.1241 \\
\hline Prime-Type*Base & 3 & 9432 & 28.71 & $<.0001^{*}$ \\
\hline ROI*Prime-Type*Base & 24 & 9432 & 0.26 & 0.9621 \\
\hline \multicolumn{5}{|c|}{ Planned comparisons Prime-Type*Base } \\
\hline \multicolumn{3}{|c|}{ Unrelated Extant vs. Related Extant } & \multicolumn{2}{|r|}{$\mathrm{t}=7.5, \mathrm{p}<.0001$} \\
\hline \multicolumn{3}{|c|}{ Unrelated NonEx1 vs. Related NonEx1 } & \multicolumn{2}{|r|}{$\mathrm{t}=11.1, \mathrm{p}<.0001$} \\
\hline \multicolumn{3}{|c|}{ Unrelated NonEx2 vs. Related NonEx2 } & \multicolumn{2}{|r|}{$\mathrm{t}=6.4, \mathrm{p}<.0001$} \\
\hline \multicolumn{4}{|c|}{ Unrelated Control NonEx vs. Related Control NonEx } & $\mathrm{t}=-1.6, \mathrm{p}=.11$ \\
\hline \multicolumn{4}{|c|}{ Difference NonEx1 - Difference NonEx2 } & $\mathrm{t}=3.3, \mathrm{p}=.001$ \\
\hline
\end{tabular}

As can be seen in the planned comparisons, a reduction in the N400 response was elicited for all morphological conditions, but not in the control condition. Figure 3 gives the mean amplitude difference between unrelated and related levels of analysis for each condition within the time window of $350 \mathrm{~ms}$ and $550 \mathrm{~ms}$ after the onset of target presentation. Distributional information is expressed in the error bars representing $95 \%$ confidence intervals for each condition. 


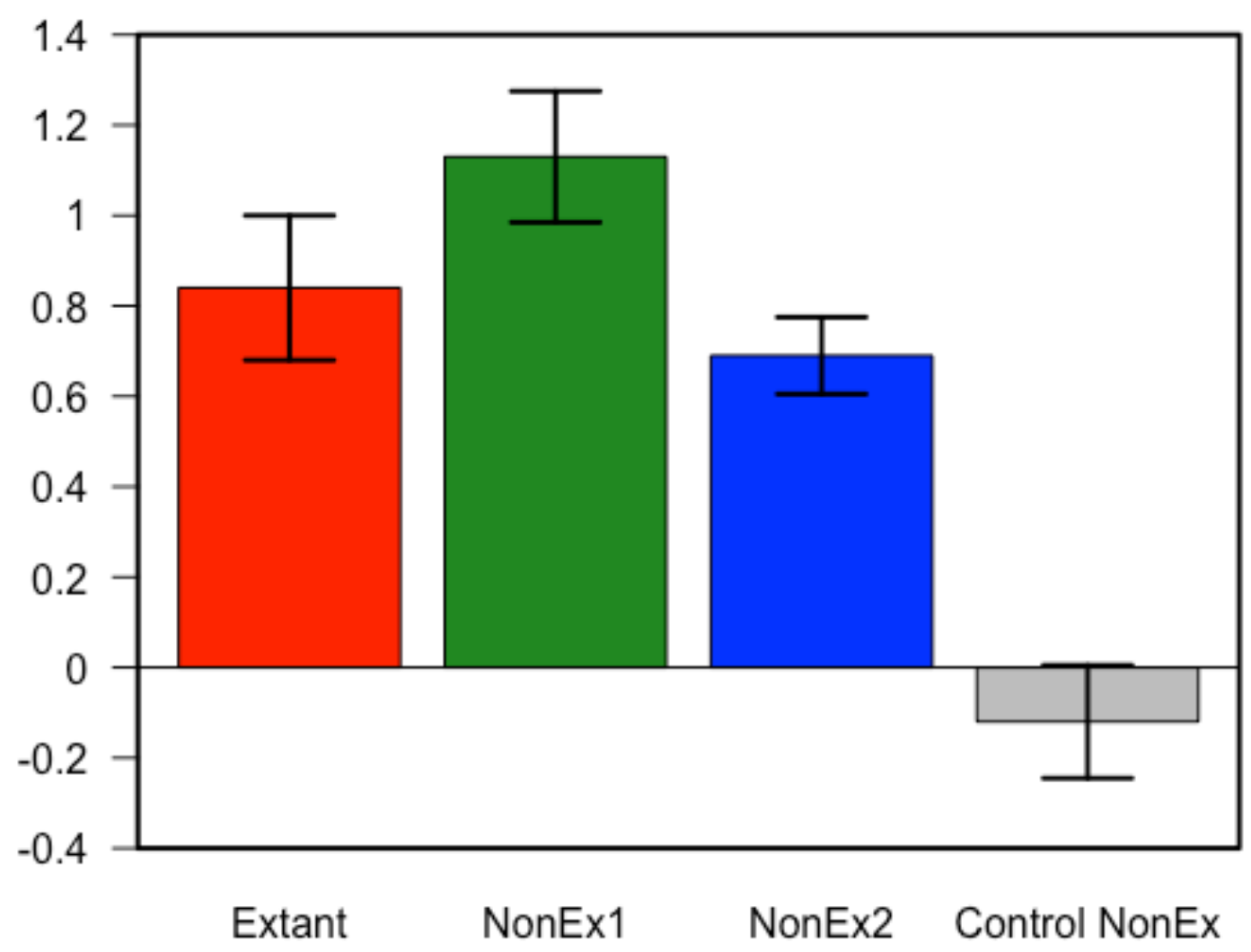

Figure 3 Mean amplitude difference between unrelated and related levels of analysis within each condition. Error bars represent $95 \%$ confidence intervals.

Waveforms for the unrelated versus related levels of analysis within each condition are given in Figure 4 for electrodes C1, Cz and C2. 


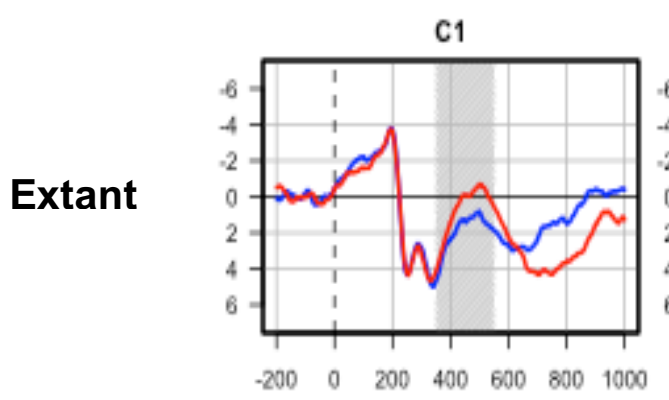

C1

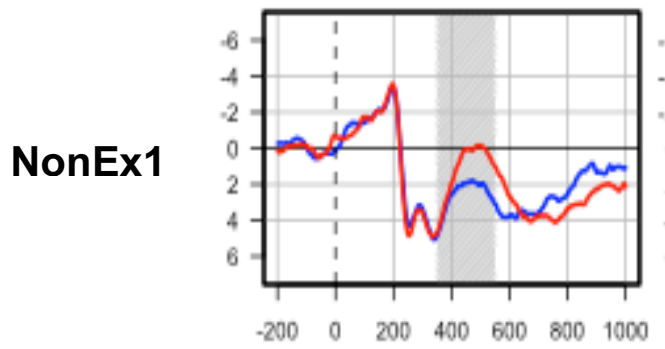

C1

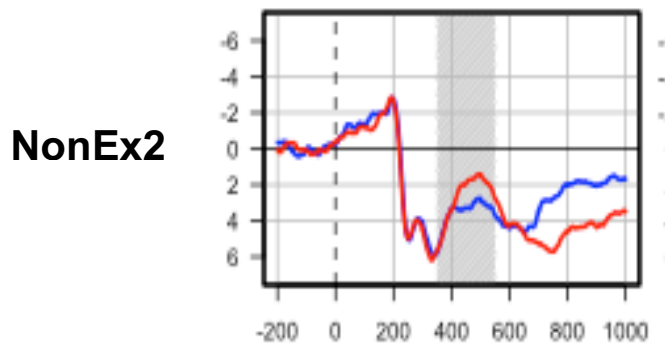

C1

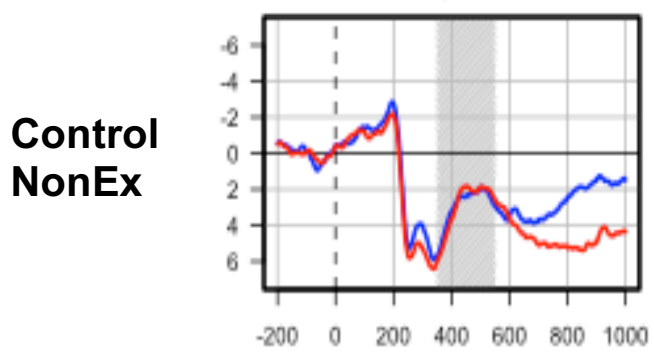

$\mathrm{Cz}$

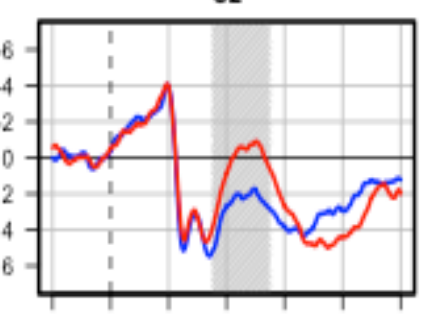

$\begin{array}{lllllll}-200 & 0 & 200 & 400 & 600 & 800 & 1000\end{array}$

$\mathrm{Cz}$

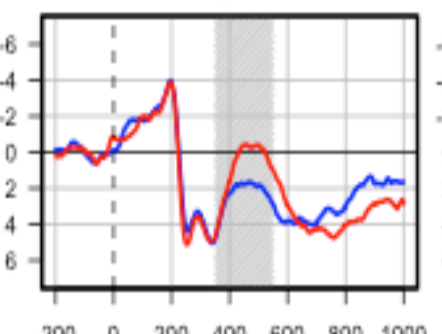

$\mathrm{Cz}$

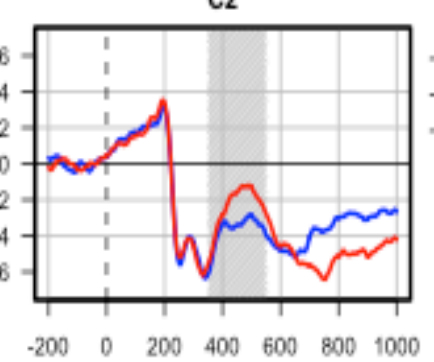

$\mathrm{Cz}$

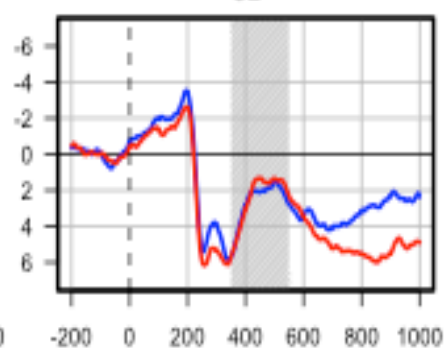

$\mathrm{C} 2$

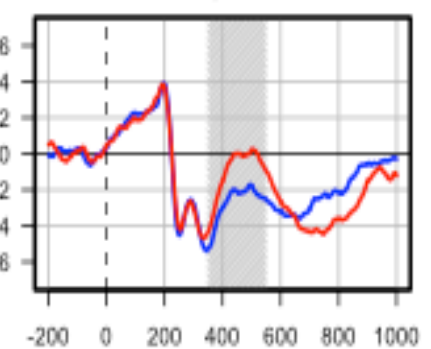

C2

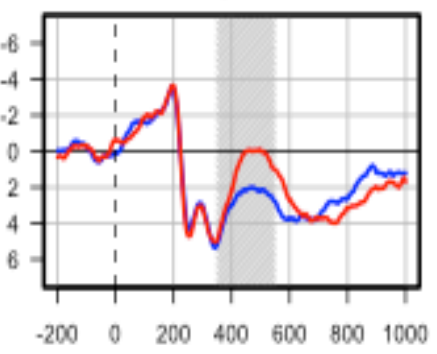

C2

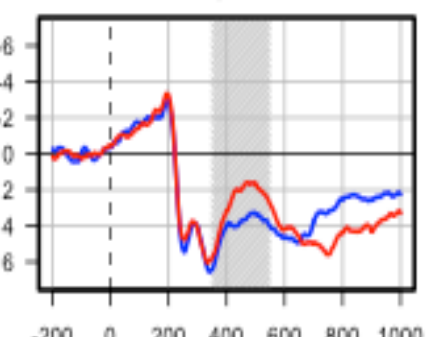

C2

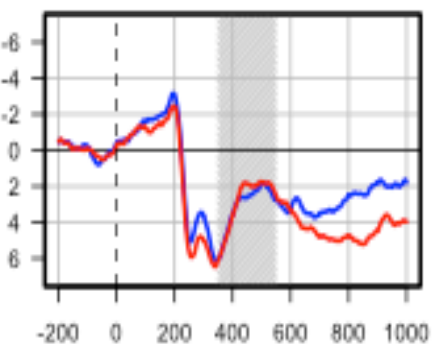

Figure 4 Waveforms for unrelated versus related levels of analysis for each condition ('Extant', 'NonEx1', 'NonEx2' and 'Control NonEx'). The area shaded in grey refers to the time window between $350 \mathrm{~ms}$ and $550 \mathrm{~ms}$ after target onset.

Given our particular interest in the processing of the two types of possible morphologically complex pseudowords, we examined possible differences in the degree of priming between related versus unrelated pairs in the two conditions. We found the priming effect for items in condition 'NonEx1' for which the intermediate position within the derivational chain is an 
existing word, to be significantly stronger (Est. $=-0.24 ; \mathrm{SE}=0.07 ; \mathrm{t}=-3.33 ; \mathrm{p}=.001$ ) than for items in 'NonEx2' (see Figure 5). This difference in priming magnitude was calculated as the difference of differences between Unrelated and Related levels within each Base (i.e. (UnrelatedNonEx1-RelatedNonEx1) - (UnrelatedNonEx2-RelatedNonEx2)).

NonEx1
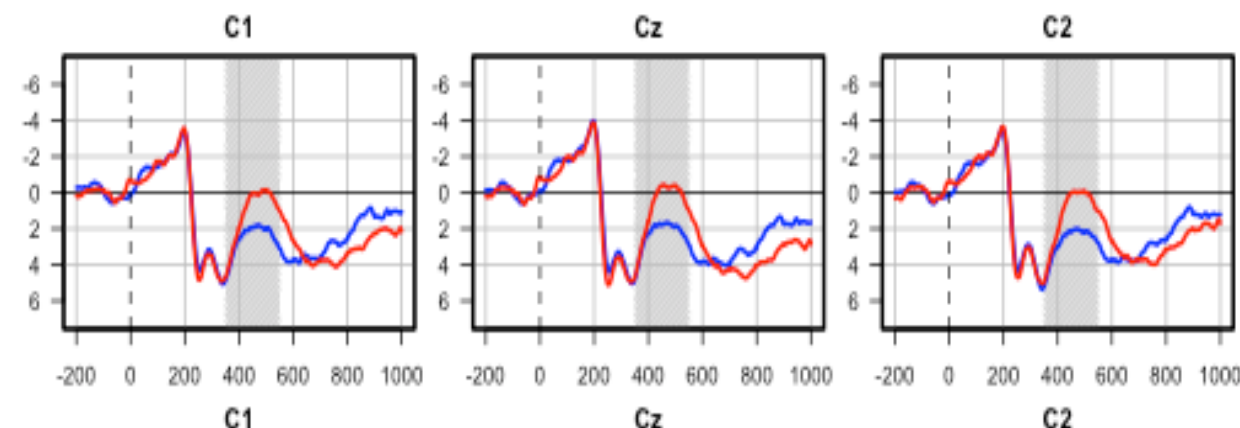

$\begin{array}{rllllll}-200 & 0 & 200 & 400 & 600 & 800 & 1000\end{array}$

$\mathrm{Cz}$

$\mathrm{C} 2$
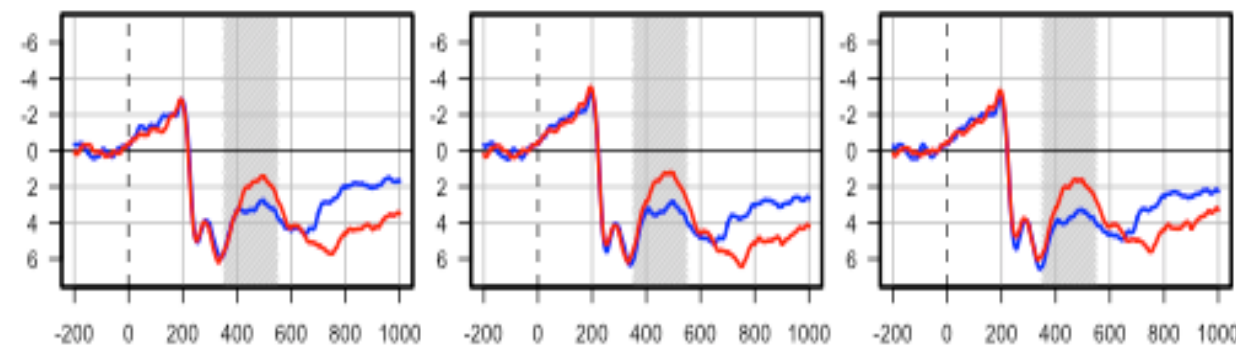

$\begin{array}{llllllllllllll}-200 & 0 & 200 & 400 & 600 & 800 & 1000 & -200 & 0 & 200 & 400 & 600 & 800 & 1000\end{array}$

Figure 5 Waveforms for unrelated versus related levels of analysis for conditions 'NonEx1' and 'NonEx2'. The area shaded in grey refers to the time window between $350 \mathrm{~ms}$ and $550 \mathrm{~ms}$ after target onset.

We also hypothesized that there may not only be differences in degree of activation, but also in timing. In order to account for possible differences in integration time between conditions, we conducted a latency analysis for the N400 component. In a factorial design crossing the Difference for each condition (Unrelated-Related) with the factor ROI, as well as with Subjects and Electrodes (nested under ROI) as random effects, we found that condition 'Extant' elicited a significantly later latency effect than any of the non-existing ('NonEx1' $(\mathrm{t}=6.5)$ and 'NonEx2' $(\mathrm{t}=5.3))$ or impossible ('Control NonEx' $(\mathrm{t}=3.13))$ conditions. Taken 
together with the differences seen in the degree of amplitude reduction between the two nonexisting forms, this suggests that future research may need to address the precise timing patterns of existing versus non-existing complex forms further.

As shown in Figure 6, differences in the processing of targets following related versus unrelated primes emerged in both morphological conditions in the N400 time window. No differences between conditions are discernible at $250 \mathrm{~ms}$ following stimulus onset. The topographies of the evoked negativity in the N400 time window are comparable in 'NonEx1' and 'NonEx2' although the distribution for 'NonEx1' appears less confined to centro-parietal electrode sites. Any negativity observed in 'Control NonEx' appears to be restricted to extremely parietal electrodes such as Oz that are not typically included in the analysis of an evoked N400 component

\section{Extant NonEx1 NonEx2 Control}
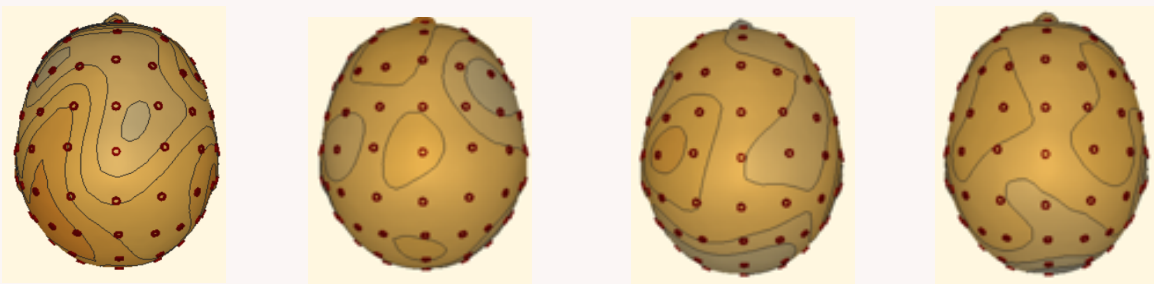

\section{$250 \mathrm{~ms}$}
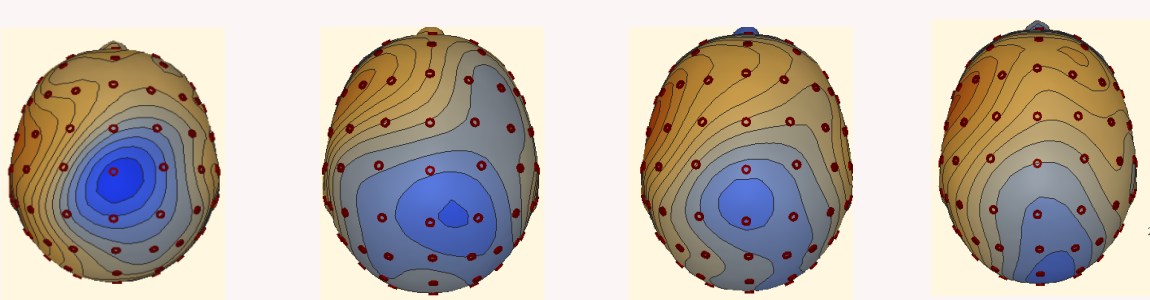

$450 \mathrm{~ms}$

Figure 6 Topographies of the evoked potentials at 250ms and 450ms following stimulus onset for targets in all experimental conditions. 
In a final step, we decided to run a follow-up analysis on the effect of the Word Category of the Base on the reduction of the N400 effect obtained. Note that within linguistic theory, a distinction is made between morphological operations that involve overt affixation processing (as is the case in our verb-based condition) versus morphological processes that draw on more subtle, covert morphological operations such as conversion. Recall that in English, conversion occurs when a change in word category, for instance verb to noun or vice versa, takes place without an overt affixational marker (e.g. an eye $>$ to eye). In the present experiment, covert derivational processes were included in the first derivational step of the adjective-based condition, whereby a verb is derived from a base adjective (e.g. heil > heilen) without the addition of an overt derivational suffix. Note that the suffix $\{-e n\}$ in German merely marks the infinitival citation form and is not a derivational suffix. The three-way interaction between Relatedness (Related vs. Unrelated), Base (Extant vs. NonEx1 vs. NonEx2 vs. Control NonEx) and Word Category (Adjective vs. Verb) reached significance at $\mathrm{p}<.001$. Planned comparisons between related and unrelated levels within each Base and Word Category revealed the following patterns across our experimental conditions:

Control NonEx: For adjective-based formations, no differences between related versus unrelated levels are observed. A highly significant inhibitory effect for verb-based formations $(t=-6.14)$ is observed, however, suggesting inhibition, rather than priming for pairings such as Dehnloslein (from dehnen (V., 'to stretch') that is combined with two suffixes $\{-l o s\}$ and $\{-\operatorname{lein}\})$

Extant: Both adjectives and verbs as bases prime significantly with a numerically larger effect for verb-based formations. The difference in priming between the two does not reach significance, however. 
NonEx1: Both adjectives and verbs as bases prime significantly, but there is no significant difference in the degree of priming.

NonEx2: Both adjectives and verbs as bases prime significantly. However, there is a statistically significant difference $(t=-2.59)$ in the degree of priming between adjectives and verbs with significantly more priming for the verb-based conditions.

Based on these results, we see that the composition of the derivational chain - both in lexicality of the form and the type of derivational process involved - modulates the processing patterns observed.

\section{General discussion}

Speech communication does not always occur under optimal conditions. Speakers can advertently or inadvertently deviate from conventional or expected output, leaving it to the listener to decode the intended meaning. In the phonological domain, Connine et al. (1993) have demonstrated that minor deviations (*GORONET instead of CORONET) can be tolerated and will lead to the activation of the word CORONET. As soon as the phonological distance between the output and the intended form becomes larger (e.g. more than two phonological features), a 'mispronounced' form such as HORONET can no longer be linked to the existing word CORONET, suggesting a gradient effect of interpretability that is contingent on the phonological distance between the intended word and its mispronunciation.

The question raised in the present paper was whether or not violations of morphological constraints would also show a gradient effect of interpretability. Previous research on morphological processing has focused on different types of violations such as agreement violations in phrases (e.g. *he eat), the application of regularisation to irregularly inflected verbs (e.g. * growed) or the addition of a suffix to a base of the wrong word class 
(e.g. *freundbar instead of freundlich in German). These and similar types of violations have been used extensively in a number of electrophysiological studies in order to obtain an understanding of the mechanisms involved in error detection and repair processes in language comprehension. By looking at the brain responses to the violations themselves, the idea has been to identify differences in the components elicited (e.g. LAN versus N400) as a means to understanding whether different types of violations would lead to specific processing signatures.

The degree to which the intended meaning was still accessible has not yet been the subject of research. In the present study, we therefore approached the question from a different angle. Here, we were concerned with the interpretability of sets of possible novel derived forms (*Spitzung and *Hübschung), as well as morphologically impossible constructions (e.g. *Wirrlein). Our interest was in the degree of activation received by the embedded base word in order to understand to what extent a structural relationship between the non-existing form and the embedded existing word could be established, suggesting that these pseudowords were interpreted as viable morphologically related forms.

Our results showed a clear difference across the three sets of non-existing items. Firstly, we found no activation of an existing form-related adjective wirr after participants were presented with impossible constructions such as *Wirrlein. Secondly, we found that novel forms such as *Spitzung (N., 'sharpening') derived through spitz (A., 'sharp') > spitzen (V., 'sharpen') > *Spitzung (N., 'sharpening') led to a stronger priming effect of their respective base than *Hübschung for which the intermediate verb form *hübschen does not exist. Note that factors that could have facilitated access to the base word such as morphological family size were matched between conditions. We would therefore argue that factors pertaining to the composition of the derivational path connecting the complex pseudoword and its base word were driving differences in processing. Recall that the two 
conditions differed in whether or not the intermediate position within the derivational path leading to the complex item was an existing word (e.g. spitzen) or a lexical gap (*hübschen). There are two ways in which this could have affected the recognition of the base word.

Firstly, it is possible that, although the overall number of morphological derivates was matched across conditions, the existence of a lexical representation in the intermediate position boosted the extent to which the overall form was semantically interpretable since cross-modal paradigms have been shown to require a semantic relationship between morphological relatives (cf. Marslen-Wilson et al., 1994). A second option would be that complex pseudowords for which the previous derivation consists of a real word activate their base words more strongly because native speakers are sensitive to the morphological rules that lead to the formation of the complex word. To be more precise, the formation of a complex noun in $\{-u n g\}$ is reliant on the availability of a verbal base. The difference between the two conditions can thus also be described as the comparison between noun formation in $\{-u n g\}$ on the basis of an actual (spitzen) versus a possible verb (*hübschen). This would point to speakers' sensitivity to the constraints that govern the formation of morphologically complex words. As discussed in a review paper by Lau, Phillips and Poeppel (2008), the N400 effect obtained in semantic priming can largely be attributed to an effect of facilitation of lexical access triggered by expectation. We would therefore argue that the results obtained suggest that an 'over-generalised' form such as *Spitzung leads to a higher degree of expectation of its base spitz than a matched novel form such as *Hübschung and its base hübsch. Increased expectation is conditional upon the existence of a derivational path that underlies the formation of both complex words as no priming is obtained for morphologically impossible controls. It is moreover driven by the lexical composition of the derivational path as evidenced by a stronger priming effect for items with fewer lexical gaps in their derivational chain such as *Spitzung, demonstrating that the composition of the derivational 
chain is considered during processing at a central, modality-independent level that is commonly tapped into using the cross-modal priming paradigm (cf. Marslen-Wilson et al., 1994; Meunier \& Longtin, 2007). What we add to the existing literature on morphological processing in cross-modal priming is that we argue for a step-wise model of morphological decomposition. Hence, for items such as *Spitzung, step-wise decomposition leads more quickly to an existing lexical representation such as spitzen than for *Hübschung, where *hübschen does not exist. For *Hübschung, one thus needs to proceed to the next stage of the decompositional procedure in order to arrive at an existing representation, which is hübsch. The differences in priming between the two sets thus point to sensitivity to morphological rules and combinatorial constraints, which affects the semantic interpretability of a novel formation.

Our findings are in conflict with the conclusions reached by previous studies on the processing of German derivational morphology. Hanna and Pulvermüller (2014), for instance, found no evidence for combinatorial processing in the derivation of German nouns given that illicit formations such as *Sicherkeit and *Sauberheit elicited a lower MMN effect than the existing formations Sicherheit and Sauberkeit. A problem that arises in the analysis of MMN data can be ascribed to the limited set of stimuli that can be employed in any condition. In the case of Hanna and Pulvermüller's study, the items *Sicherkeit and *Sauberheit are selected as the deviant stimuli that are meant to represent the suffixation processes with an illicit suffix. However, as the authors discuss in later portions of the paper, the complex word Sicherheit is significantly more frequent than Sauberkeit. Moreover, it could also be argued that *Sicherkeit displays a violation that is qualitatively different from the one observed in *Sauberheit. Following the prosodic constraints advanced by Janssen et al. (2006) on the basis of Fleischer, Barz and Schröder (1995), \{-keit $\}$ is selected following unstressed syllables. In view of this common distribution, Sicherheit could be considered to 
be more marked than Sauberkeit. Hanna and Pulvermüller (2014) indeed find a main effect of the root with both formations based on sicher eliciting stronger responses than formations based on sauber. The higher 'baseline' effect for formations based on sicher could suggest that already the existing formation Sicherheit is marked and leads to a stronger effect than Sauberkeit. While it is also possible that these differences in the baseline magnitude for existing items are attributable due to a higher frequency of the base word in sicher, both explanations of these baseline differences between the two conditions essentially point to a common problem in the design of MMN experiments: the selection of stimuli is crucial and any idiosyncrasies of form selected for a particular condition may affect the overall result. Moreover, a clear characterisation of the type of violation investigated is crucial. Although Hanna and Pulvermüller (2014) and Janssen et al. (2006) refer to similar sets of morphological violations in derivation, the rules underlying the formation of these forms are interpreted differently between the two studies. In the former study, the distribution between $\{-k e i t\}$ and $\{-h e i t\}$ is claimed to be arbitrary while the latter study provides the phonological constraints that govern their distribution. Thus, it appears to be inherently difficult to investigate the processing of morphological violation and mapping types of morphological violation to distinct processing signatures if there is disagreement over the nature of the violation involved.

The same problem applies to the stimuli selected by Janssen et al. (2006) who found an N400, rather than a LAN effect for pseudowords such as *Vollung. While Janssen et al. (2006) argue that the formation *Vollung consists of a combination of the stem voll and the deverbal suffix $\{-u n g\}$, it is possible that an intermediate verb *vollen is considered during processing, yielding a viable derivational path voll (A., 'full') $>*$ vollen (V., 'to fill') $>$ *Vollung (N., 'filling'). Based on the results in the present experiment, it appears that these intermediate verb forms can in fact be computed and are considered morphologically viable 
during processing. This conclusion is supported by the absence of any priming for pairs such as *Wirrlein and wirr (A., 'confused') in the present study. If pseudowords such as *Hübschung in condition 'NonEx2' were interpreted as a morphosyntactic violation in which the deverbal suffix $\{-$ ung $\}$ attaches to an adjectival base, then the processing patterns between 'NonEx2' and 'Control NonEx' would have been expected to be similar. Instead, we have clear evidence that an attenuation of the N400 only occurs following non-existing forms that are morphologically well-formed.

Overall, the present results suggest that the 'over-application' of a morphological rule to a possible pseudoword leads to mispronunciations that permit the activation of the respective base word. The degree to which the base becomes accessible differs, however, depending on the lexical status of the derivation immediately preceding the formation of the complex pseudowords. Thus, even though the sets in 'NonEx1' and 'NonEx2' do not appear dissimilar on a surface level, items in 'NonEx1' such as *Spitzung show stronger activation for the base word spitz, arguably because the existence of a lexical representation for the intermediate derivation lends additional plausibility to the pseudoword. Intermediate levels of derivational structure are thus accessed following the auditory presentation with a morphologically viable pseudoword. The lexicality of the final noun form also affects processing - if not significantly in the degree of priming obtained, then in the latency of the integration effect with a later peak in the 'Ex' condition than in any of the non-existing conditions. Morphologically unviable formations such as *Wirrlein, on the other hand, do not provide a context that allows the integration of an existing word with which it merely shares some formal overlap. Both the structural rules of morphological derivation, as well as the mental lexicon are thus factors that determine the extent to which novel forms can activate a related existing word. In our study, we saw evidence for the idea that structure can refer to both the combinatory possibility between base and affix (conditions 'NonEx1' and 'NonEx2' 
vs. 'Control NonEx'), as well as to the type of derivational process involved (adjective- vs. verb-based). As we mention previously, in linguistic theory, particularly within the theory of lexical phonology (Kiparsky, 1982), a distinction is made between different types of morphological process involved (conversion-based processes versus overt affixation). The results of our follow-up analysis that included the factor Word Category seem to support this hypothesis with more robust priming effects in morphological processes that show overt affixation throughout the derivational chain. Since at this point it is impossible to be certain whether these differences are driven by the word category of the base word (adjective vs. verb) or by the type of derivational process involved in the intermediate position of the derivational chain (conversion vs. suffixation), a number of further experiments will be required to investigate the cause for these processing differences further. Either explanation, whether it is the type of base or the type of derivational processes involved during processing, lend further support to the notion of sensitivity to intermediate levels of morphological complexity, even in a cross-modal processing context.

As the first cross-modal repetition priming study investigating morphological processing with different sets of complex pseudowords, we find that the paradigm is wellsuited to an assessment of the extent to which different types of morphological violations lead to the activation of their bases. The paradigm can be used in conjunction with MMNs and unprimed lexical decision tasks as a means of gauging the degree of 'interpretability', rather than the degree of 'violation' of different types of complex and pseudocomplex novel forms, thereby providing a window into the mechanisms that enable listeners to interpret novel forms, as well as different levels of deviation in the language input with which they are presented. 


\section{Acknowledgements}

The work was supported by an ESRC Doctoral Training Grant (grant number: ES/J500112/1) awarded to Swetlana Schuster and by a Horizon 2020 ERC Advanced Grant to Aditi Lahiri (MORPHON 695481). We would like to thank Colin Brooks and Steven Kaye for their helpful comments on previous versions of this manuscript, Sandra Kotzor for the recording of the German auditory stimuli and Harry Fischl for assistance with data visualisation. The R scripts for the generation of our waveforms were kindly provided to us by Mante Nieuwland. We have no conflicts of interest to declare. 


\section{References}

Aronoff, M. (1976). Word formation in generative grammar. Cambridge (Mass.): MIT Press.

Baayen, R.H., Piepenbrock, R., \& Gulikers, L. (1995). The CELEX Lexical Database (Release 2). Philadelphia, PA: Linguistic Data Consortium, University of Pennsylvania [http://web.phonetik.uni-frankfurt.de/simplex.html].

Bakker, I., MacGregor, L., Pulvermüller, F., \& Shtyrov, Y. (2013). Past tense in the brain's time: Neurophysiological evidence for dual-route processing of past-tense verbs. Neuroimage, 71, 187-195. http://dx.doi.org/10.1016/j.neuroimage.2012.12.065

Bölte, J., Jansma, B., Zilverstand, A., \& Zwitserlood, P. (2009). Derivational morphology approached with event-related potentials. The Mental Lexicon, 4(3), 336-353. http://dx.doi.org/10.1075/ml.4.3.02bol

Bölte, J., Schulz, C., \& Dobel, C. (2010). Processing of existing, synonymous, and anomalous German derived adjectives: An MEG study. Neuroscience Letters, 469(1), 107-111. doi: 10.1016/j.neulet.2009.11.054

Bybee, J. (2001). Phonology and language use. Cambridge: Cambridge University Press.

Connine, C., Blasko, D., \& Titone, D. (1993). Do the beginnings of spoken words have a special status in auditory word recognition? Journal of Memory and Language, 32(2), 193-210. http://dx.doi.org/10.1006/jmla.1993.1011

Fleischer, W., Barz, I., \& Schröder, M. (1995). Wortbildung der deutschen Gegenwartssprache. Tübingen: Niemeyer.

Grainger, J., \& Beyersmann, E. (2017). Edge-aligned embedded word activation initiates morpho-orthographic segmentation. In B. H. Ross (Ed.), The Psychology of Learning and Motivation (pp. 285-317). 
Hanna, J., \& Pulvermüller, F. (2014). Neurophysiological evidence for whole form retrieval of complex derived words: a mismatch negativity study. Frontiers in Human Neuroscience, 8:886. doi:10.3389/fnhum.2014.00886

Ille, N., Berg, P., \& Scherg, M., (2002). Artifact correction of the ongoing EEG using spatial filters based on artifact and brain signal topographies. Journal of Clinical Neurophysiology, 19, 113-124.

Isitt, D. (1983). Crazic, menty and idiotal: an inquiry into the use of suffixes -al, -ic, -ly and $y$ in modern English. Humanities Pr.

Janssen, U., Wiese, R., \& Schlesewsky, M. (2006). Electrophysiological responses to violations of morphosyntactic and prosodic features in derived German nouns. Journal of Neurolinguistics, 19(6), 466-482. http://dx.doi.org/10.1016/j.jneuroling.2006.04.002

Kiparsky, P. (1982). Lexical Morphology and Phonology. In The Linguistic Society of Korea (Ed.), Linguistics in the Morning Calm (pp. 1-91). Seoul: Hanshin Publishing Co.

Klein, W., \& Geyken, A. (2010). Das digitale Wörterbuch der deutschen Sprache (DWDS). Lexicographica, 26, 79-96. Retrieved 7 Dec. 2017.

Lahiri, A. (2012). Asymmetric phonological representations of words in the mental lexicon. In A. Cohn, The Oxford Handbook of Laboratory Phonology (pp. 146-161). Oxford: OUP.

Lahiri, A., \& Reetz, H. (2002). Underspecified recognition. In C. Gussenhoven \& N. Warner (Eds.), Laboratory Phonology VII (pp.637-677). Berlin: Mouton de Gruyter.

Lau, E., Phillips, C., \& Poeppel, D. (2008). A cortical network for semantics: (de)constructing the N400. Nature Reviews Neuroscience, 9(12), 920-933. http://dx.doi.org/10.1038/nrn2532 
Leinonen, A., Brattico, P., Järvenpää, M., \& Krause, C. (2008). Event-related potential (ERP) responses to violations of inflectional and derivational rules of Finnish. Brain Research, 1218, 181-193. http://dx.doi.org/10.1016/j.brainres.2008.04.049

Linares, R., Rodriguez-Fornells, A., \& Clahsen, H. (2006). Stem allomorphy in the Spanish mental lexicon: Evidence from behavioral and ERP experiments. Brain and Language, 97(1), 110-120. http://dx.doi.org/10.1016/j.bandl.2005.08.008

Longtin, C., \& Meunier, F. (2005). Morphological decomposition in early visual word processing. Journal of Memory and Language, 53(1), 26-41. http://dx.doi.org/10.1016/j.jml.2005.02.008

Lück, M., Hahne, A., \& Clahsen, H. (2006). Brain potentials to morphologically complex words during listening. Brain Research, 1077(1), 144-152. http://dx.doi.org/10.1016/j.brainres.2006.01.030

Marchand, H. (1969). The categories and types of present-day English word-formation. München: Beck.

Marslen-Wilson, W., Tyler, L., Waksler, R., \& Older, L. (1994). Morphology and meaning in the English mental lexicon. Psychological Review, 101(1), 3-33.

Meinzer, M., Lahiri, A., Flaisch, T., Hannemann, R., \& Eulitz, C. (2009). Opaque for the reader but transparent for the brain: Neural signatures of morphological complexity. Neuropsychologia, 47(8-9), 1964-1971.

Meunier, F., \& Longtin, C. (2007). Morphological decomposition and semantic integration in word processing. Journal of Memory and Language, 56(4), 457-471. http://dx.doi.org/10.1016/j.jml.2006.11.005

Morris, J., \& Holcomb, P. (2005). Event-related potentials to violations of inflectional verb morphology in English. Cognitive Brain Research, 25(3), 963-981. http://dx.doi.org/10.1016/j.cogbrainres.2005.09.021 
Morris, J., Porter, J., Grainger, J., \& Holcomb, P. (2011). Effects of lexical status and morphological complexity in masked priming: An ERP study. Language and Cognitive Processes, 26(4-6), 558-599. http://dx.doi.org/10.1080/01690965.2010.495482

Oldfield, R. (1971). The assessment and analysis of handedness: The Edinburgh inventory. Neuropsychologia, 9(1), 97-113. http://dx.doi.org/10.1016/0028-3932(71)90067-4

Penke, M., Weyerts, H., Gross, M., Zander, E., Münte, T., \& Clahsen, H. (1997). How the brain processes complex words: an event-related potential study of German verb inflections. Cognitive Brain Research, 6(1), 37-52. http://dx.doi.org/10.1016/s0926$\underline{6410(97) 00012-8}$

Pierrehumbert, J. (2016). Phonological Representation: Beyond abstract versus episodic. Annual Review of Linguistics, 2(1), pp.33-52. https://doi.org/10.1146/annurev-linguistics-030514-125050

Pliatsikas, C., Wheeldon, L., Lahiri, A., \& Hansen, P. (2014). Processing of zero-derived words in English: An fMRI investigation. Neuropsychologia, 53, 47-53.

Pulvermüller, F., Kujala, T., Shtyrov, Y., Simola, J., Tiitinen, H., \& Alku, P. et al. (2001). Memory Traces for Words as Revealed by the Mismatch Negativity. Neuroimage, 14(3), 607-616. http://dx.doi.org/10.1006/nimg.2001.0864

Pulvermüller, F., Shtyrov, Y., Hasting, A., \& Carlyon, R. (2008). Syntax as a reflex: Neurophysiological evidence for early automaticity of grammatical processing. Brain and Language, 104(3), 244-253. http://dx.doi.org/10.1016/j.bandl.2007.05.002

Rastle, K., Davis, M., \& New, B. (2004). The broth in my brother's brothel: Morphoorthographic segmentation in visual word recognition. Psychonomic Bulletin \& Review, 11(6), 1090-1098. http://dx.doi.org/10.3758/bf03196742

Roberts, A., Kotzor, S., Wetterlin, A., \& Lahiri, A. (2014). Asymmetric processing of durational differences - Electrophysiological investigations in Bengali. 
Neuropsychologia, 58, 88-98.

http://dx.doi.org/10.1016/j.neuropsychologia.2014.03.015

Rodriguez-Fornells, A., Clahsen, H., Lleó, C., Zaake, W., \& Münte, T. (2001). Event-related brain responses to morphological violations in Catalan. Cognitive Brain Research, 11(1), 47-58. http://dx.doi.org/10.1016/s0926-6410(00)00063-x

Schuster, S., \& Lahiri, A. (2018). Lexical gaps and morphological decomposition: Evidence from German. Journal of Experimental Psychology: Learning, Memory, and Cognition. doi: 10.1037/xlm0000560

Schuster, S., Scharinger, M., Brooks, C., Lahiri, A., \& Hartwigsen, G. (2018). The neural correlates of morphological complexity processing: Detecting structure in pseudowords. Human Brain Mapping, 39(6), 2317-2328.doi:10.1002/hbm.23975

Smolka, E., Gondan, M., \& Rösler, F. (2015). Take a stand on understanding: electrophysiological evidence for stem access in German complex verbs. Frontiers in Human Neuroscience, 9. http://dx.doi.org/10.3389/fnhum.2015.00062

Shtyrov Y., \& Pulvermüller, F. (2002). Neurophysiological evidence of memory traces for words in the human brain. Neuroreport, 13, 521-525 10.1097/00001756-20020325000033

Wheeldon, L., Schuster, S., Pliatsikas, C., Malpass, D., \& Lahiri, A. (2018). Beyond decomposition: Processing zero-derivations in English visual word recognition. Cortex. doi: 10.1016/j.cortex.2018.09.003 
APPENDIX: List of prime-target pairings for all four experimental conditions

\section{Condition 'Extant'}

\begin{tabular}{|c|c|c|}
\hline Unrelated Prime & Related Prime & Target \\
\hline \multicolumn{3}{|r|}{ Adjective as Base } \\
\hline Impfung & Kühlung & kühl \\
\hline Spüler & Bräunung & braun \\
\hline Heimweh & Zähmung & zahm \\
\hline Sorgfalt & Heilung & heil \\
\hline Pfleger & Schwächung & schwach \\
\hline Bäuchlein & Reifung & reif \\
\hline Teelicht & Rötung & rot \\
\hline Schlauheit & Kränkung & krank \\
\hline Laschheit & Glättung & glatt \\
\hline Deckung & Härtung & hart \\
\hline Drücker & Wärmung & warm \\
\hline Mahnung & Tötung & tot \\
\hline Gleichnis & Schlichtung & schlicht \\
\hline Trübsal & Krümmung & krumm \\
\hline Neuheit & Lähmung & lahm \\
\hline Furchung & Höhlung & hohl \\
\hline Bötchen & Querung & quer \\
\hline Gärtner & Wertung & wert \\
\hline Lüfter & Leerung & leer \\
\hline Niesreiz & Schwärzung & schwarz \\
\hline
\end{tabular}




\begin{tabular}{|c|c|c|}
\hline \multicolumn{3}{|c|}{ Verb as Base } \\
\hline Keksdose & Teilbarkeit & teilen \\
\hline Flugverkehr & Wählbarkeit & wählen \\
\hline Ausstrahlung & Sichtbarkeit & sichten \\
\hline Kleidungsstück & Kostbarkeit & kosten \\
\hline Fahndungen & Mischbarkeit & mischen \\
\hline Beiordnung & Heilbarkeit & heilen \\
\hline Sprengpulver & Reizbarkeit & reizen \\
\hline Fertigkeit & Messbarkeit & messen \\
\hline Farbkasten & Greifbarkeit & greifen \\
\hline Überstrumpf & Trennbarkeit & trennen \\
\hline Trostworte & Achtbarkeit & achten \\
\hline Pflaumenbaum & Formbarkeit & formen \\
\hline Standardwert & Brennbarkeit & brennen \\
\hline Kugelform & Ehrbarkeit & ehren \\
\hline Lebensziel & Lesbarkeit & lesen \\
\hline Lohnsteuern & Dankbarkeit & danken \\
\hline Abfahrtszeit & Störbarkeit & stören \\
\hline Dienstzeiten & Schmelzbarkeit & schmelzen \\
\hline Sattelgurt & Planbarkeit & planen \\
\hline Stichwunde & Waschbarkeit & waschen \\
\hline
\end{tabular}


Condition 'NonEx1'

\begin{tabular}{|c|c|c|}
\hline Unrelated Prime & Related Prime & Target \\
\hline \multicolumn{3}{|r|}{ Adjective as Base } \\
\hline Schrägnis & Liebung & lieb \\
\hline Kleinnis & Läutung & laut \\
\hline Jähnis & Grünung & grün \\
\hline Sträffe & Bleichung & bleich \\
\hline Flautum & Fettung & fett \\
\hline Schrofftum & Feuchtung & feucht \\
\hline Gröbnis & Nässung & nass \\
\hline Sättnis & Süßung & süß \\
\hline Purtum & Spitzung & spitz \\
\hline Barheit & Frischung & frisch \\
\hline Knäppnis & Engung & eng \\
\hline Dichtnis & Stillung & still \\
\hline Chictum & Welkung & welk \\
\hline Grelle & Faulung & faul \\
\hline Sanfttum & Weichung & weich \\
\hline Schlaunis & Breitung & breit \\
\hline Strikttum & Scheuung & scheu \\
\hline Täube & Reichung & reich \\
\hline Schlacknis & Schrillung & schrill \\
\hline Plättnis & Schrägung & schräg \\
\hline \multicolumn{3}{|r|}{ Verb as Base } \\
\hline Lockbarkeit & Tastbarkeit & tasten \\
\hline Schliessbarkeit & Scheinbarkeit & scheinen \\
\hline Brüllbarkeit & Rauchbarkeit & rauchen \\
\hline Ahndbarkeit & Schmiedbarkeit & schmieden \\
\hline Endbarkeit & Beugbarkeit & beugen \\
\hline Hängbarkeit & Spürbarkeit & spüren \\
\hline Hörbarkeit & Fassbarkeit & fassen \\
\hline Zahlbarkeit & Denkbarkeit & denken \\
\hline Scheidbarkeit & Druckbarkeit & drucken \\
\hline Klatschbarkeit & Streichbarkeit & streichen \\
\hline Schippbarkeit & Schmeckbarkeit & schmecken \\
\hline Bahnbarkeit & Biegbarkeit & biegen \\
\hline Schaffbarkeit & Trinkbarkeit & trinken \\
\hline
\end{tabular}




\begin{tabular}{|l|l|l|}
\hline Saugbarkeit & Fühlbarkeit & fühlen \\
\hline Forschbarkeit & Heizbarkeit & heizen \\
\hline Platzbarkeit & Knetbarkeit & kneten \\
\hline Klebbarkeit & Schlachtbarkeit & schlachten \\
\hline Filmbarkeit & Zollbarkeit & zollen \\
\hline Henkbarkeit & Brechbarkeit & brechen \\
\hline Juckbarkeit & Rettbarkeit & retten \\
\hline
\end{tabular}

\section{Condition 'NonEx2'}

\begin{tabular}{|l|l|l|}
\hline Unrelated Prime & Related Prime & Target \\
\hline \multicolumn{2}{|l|}{ Adjective as Base } \\
\hline Prompttum & Armung & arm \\
\hline Zähnis & Blondung & blond \\
\hline Steifung & Nettung & nett \\
\hline Böstum & Fernung & fern \\
\hline Raschung & Hübschung & hübsch \\
\hline Schärfnis & Stolzung & stolz \\
\hline Schiefung & Nacktung & nackt \\
\hline Frechnis & Stummung & stumm \\
\hline Schmalung & Mildung & mild \\
\hline Frohheit & Schlimmung & schlimm \\
\hline Echtung & Brävung & brav \\
\hline Röhnis & Zärtung & zart \\
\hline Blänknis & Kühnung & kühn \\
\hline Tiefung & Bläuung & blau \\
\hline Wehung & Dummung & dumm \\
\hline Lassung & Kältung & kalt \\
\hline Buntung & Treuung & treu \\
\hline Sturung & Strengung & streng \\
\hline Ernstnis & Jüngung & jung \\
\hline Klugtum & Dünnung & dünn \\
\hline & Kämpfbarkeit & kämpfen \\
\hline Rächbarkeit & Weichbarkeit & weichen \\
\hline Jagbarkeit & Herrschbarkeit & herrschen \\
\hline Bittbarkeit & Verb as Base \\
\hline
\end{tabular}




\begin{tabular}{|l|l|l|}
\hline Sicherschaft & Hoffbarkeit & hoffen \\
\hline Neigbarkeit & Siegbarkeit & siegen \\
\hline Wahrbarkeit & Sterbbarkeit & sterben \\
\hline Atmeschaft & Drängbarkeit & drängen \\
\hline Öffneschaft & Kriegbarkeit & kriegen \\
\hline Erntbarkeit & Büßbarkeit & büßen \\
\hline Tanzbarkeit & Weinbarkeit & weinen \\
\hline Heißbarkeit & Reisbarkeit & reisen \\
\hline Passbarkeit & Werbbarkeit & werben \\
\hline Ankerschaft & Erbbarkeit & erben \\
\hline Fügbarkeit & Badbarkeit & baden \\
\hline Grinsbarkeit & Blutbarkeit & bluten \\
\hline Sprengbarkeit & Grüßbarkeit & grüßen \\
\hline Richtbarkeit & Laufbarkeit & laufen \\
\hline Nervbarkeit & Scheuchbarkeit & scheuchen \\
\hline Klimmbarkeit & Schellbarkeit & schellen \\
\hline Landbarkeit & Schenkbarkeit & schenken \\
\hline
\end{tabular}

\section{Condition 'Control NonEx'}

\begin{tabular}{|c|c|c|}
\hline Unrelated Prime & Related Prime & Target \\
\hline \multicolumn{3}{|r|}{ Adjective as Base } \\
\hline Mättlein & Steillein & steil \\
\hline Nähsal & Räuler & rau \\
\hline Blödlein & Plümpsal & plump \\
\hline Wildsal & Gelbsal & gelb \\
\hline Derbsal & Strammlein & stramm \\
\hline Kahllein & Blassler & blass \\
\hline Frömmsal & Flöttlein & flott \\
\hline Fädsal & Fixlein & fix \\
\hline Ärgsal & Flächler & flach \\
\hline Reinlein & Frühler & früh \\
\hline Stärrsal & Stillsal & bloß \\
\hline Währsal & Länglein & lang \\
\hline Schierlein & Töllsal & toll \\
\hline Kecksal & Flinkler & flink \\
\hline
\end{tabular}




\begin{tabular}{|c|c|c|}
\hline Blindsal & Hellsal & hell \\
\hline Döfler & Dreistsal & dreist \\
\hline Leidlein & Fairsal & fair \\
\hline Spätlein & Heißler & heiß \\
\hline Dürrsal & Wirrler & wirr \\
\hline Deutschlein & Wächlein & wach \\
\hline \multicolumn{3}{|c|}{ Verb as Bas } \\
\hline Sausloslein & Flatterlossal & flattern \\
\hline Kennloslein & Leistlossel & leisten \\
\hline Klauloslein & Dehnloslein & dehnen \\
\hline Füllossal & Legensel & legen \\
\hline Sitzlossal & Weislossal & weisen \\
\hline Fanglosler & Schätzlosler & schätzen \\
\hline Drehschung & Trauschung & trauen \\
\hline Bremloslein & Kehrloslein & kehren \\
\hline Nählosler & Spannensel & spannen \\
\hline Pfeiflossal & Hasslossal & hassen \\
\hline Fliehlosler & Schieblosler & schieben \\
\hline Hauloslein & Tummloslein & tummeln \\
\hline Sparloslein & Waglosler & wagen \\
\hline Tarnlossal & Fastlossal & fasten \\
\hline Schreiloslein & Warnenlein & warnen \\
\hline Lachlosler & Schlaflossal & schlafen \\
\hline Kränklossal & Blendlossal & blenden \\
\hline Dienensel & Fördensel & fördern \\
\hline Schiffloslein & Eignenung & eignen \\
\hline Spaltenler & Häuflosler & häufen \\
\hline
\end{tabular}

